\title{
Comparison of Physicochemical Properties of Starches from Nine Chinese Chestnut Varieties
}

\author{
Long Zhang ${ }^{1,2}\left(\mathbb{D}\right.$, Tianxiang Liu ${ }^{1,2}$, Guanglong $\mathrm{Hu}^{3}{ }^{(D}$, Ke Guo $^{1,2}$ and Cunxu Wei ${ }^{1,2, *(D)}$ \\ 1 Key Laboratory of Crop Genetics and Physiology of Jiangsu Province / Key Laboratory of Plant Functional \\ Genomics of the Ministry of Education, Yangzhou University, Yangzhou 225009, China; \\ zhanglong@yzu.edu.cn (L.Z.); tianxiangliu1993@163.com (T.L.); 18115657147@163.com (K.G.) \\ 2 Co-Innovation Center for Modern Production Technology of Grain Crops of Jiangsu Province / Joint \\ International Research Laboratory of Agriculture \& Agri-Product Safety of the Ministry of Education, \\ Yangzhou University, Yangzhou 225009, China \\ 3 Institute of Forest and Pomology, Beijing Academy of Agricultural and Forestry Sciences, \\ Beijing 100093, China; hglcau@gmail.com \\ * Correspondence: cxwei@yzu.edu.cn
}

Academic Editors: Mingfu Wang and Yueliang Zhao

Received: 14 November 2018; Accepted: 4 December 2018; Published: 7 December 2018

\begin{abstract}
Chestnut is a popular food in many countries and is also an important starch source. In previous studies, physicochemical properties of starches have been compared among different Chinese chestnut varieties growing under different conditions. In this study, nine Chinese chestnut varieties from the same farm were investigated for starch physicochemical properties to exclude the effects of growing conditions. The dry kernels had starch contents from 42.7 to $49.3 \%$. Starches from different varieties had similar morphologies and exhibited round, oval, ellipsoidal, and polygonal shapes with a central hilum and smooth surface. Starch had bimodal size distribution and the volume-weighted mean diameter ranged from 7.2 to $8.2 \mu \mathrm{m}$ among nine varieties. The starches had apparent amylose contents from 23.8 to $27.3 \%$ but exhibited the same C-type crystalline structure and similar relative crystallinity, ordered degree, and lamellar structure. The gelatinization onset, peak, and conclusion temperatures ranged from 60.4 to $63.9{ }^{\circ} \mathrm{C}$, from 64.8 to $68.3^{\circ} \mathrm{C}$, and from 70.5 to $74.5^{\circ} \mathrm{C}$, respectively, among nine starches; and the peak, hot, breakdown, final, and setback viscosities ranged from 5524 to $6505 \mathrm{mPa}$ s, from 3042 to $3616 \mathrm{mPa} \mathrm{s}$, from 2205 to $2954 \mathrm{mPa}$ s, from 4378 to $4942 \mathrm{mPa}$ s, and from 1326 to $1788 \mathrm{mPa}$ s, respectively. The rapidly digestible starch, slowly digestible starch, and resistant starch ranged from 2.6 to $3.7 \%$, from 5.7 to $12.7 \%$, and from 84.4 to $90.7 \%$, respectively, for native starch, and from 79.6 to $89.5 \%$, from 1.3 to $3.8 \%$, and from 7.1 to $17.4 \%$, respectively, for gelatinized starch.
\end{abstract}

Keywords: Chinese chestnut; starch; structural properties; thermal properties; pasting properties; digestion properties

\section{Introduction}

Starch is synthesized and stored as semi-crystalline granules in seeds, fruits, and some metamorphic roots and stems [1-3]. Starch is widely used not only as foods to provide nutrition for humans and animals, but also as raw materials for food and nonfood processing industries. Starches from different plant sources have different physicochemical properties, which determine their different applications [1-3]. The investigation of starch physicochemical properties is mainly focused on conventional starch sources such as cereal seeds, legume seeds, tuber crops, and some root tubers [1-5]. With the increasing demand for starch in food and nonfood industries, some nonconventional starch sources have been investigated in recent years [6-10]. 
Chestnuts are the fruits of Castanea spp. which belong to the beech family Fagaceae [11]. In 2016, the world production of chestnut reached about 2.26 million tons, and came from Asia $(89.8 \%)$, Europe $(6.3 \%)$, and the Americas $(3.9 \%)$. The top five producers were Bolivia (about 0.08 million tons), China (about 1.88 million tons), Italy (about 0.05 million tons), Korea (about 0.6 million tons), and Turkey (about 0.06 million tons) [12]. The chestnut production in China reached about $83.1 \%$ of world production in 2016 [12]. The major cultivated species of edible chestnuts include the Chinese chestnut (Castanea mollissima) in China and Korea, Castanea sativa in Europe and South America, and Castanea crenata in Japan [11]. The edible kernel of chestnut contains some important functional components, such as polyphenols, vitamins, dietary fibers, minerals, and unsaturated fatty acids. The consumption of chestnut kernels has health benefits including anti-tumor, antimicrobial, and antioxidants [13,14]. Therefore, chestnuts have become an important and popular food in many countries.

The dry kernel of a chestnut contains about $50 \%$ starch and is an important starch source [15-18]. Therefore, there are many studies on chestnut starch [15-28]. The physicochemical properties of chestnut starches are mainly focused on C. sativa $[15,17,19-21]$ and the Chinese chestnut $[16,18,22-28]$. For Chinese chestnuts, the effects of drying methods and thermal processing on structural and functional properties of starch have been reported in some literatures $[22,24,25,27]$. The identification and expression of starch synthesis related genes are analyzed during kernel development of Chinese chestnuts $[26,28]$. The physicochemical properties of starches are compared among different Chinese chestnut varieties [16,18]. For examples, Liu et al. [16] investigated the structural and functional properties of starches from four Chinese chestnut varieties and found that starches have significantly different morphologies and granule sizes, but have similar amylose contents and the same crystalline type. Hao et al. [18] investigated the physicochemical characteristics of starches from six Chinese chestnut varieties growing in different geographical conditions and found that the varieties and geographical distribution significantly influence the characteristics of chestnut starch. A large number of Chinese chestnut varieties have been cultivated in China. The different growing conditions influence the physicochemical properties of starches. Therefore, it is very important to investigate the physicochemical properties of starches from different varieties growing under the same conditions. However, such studies are little reported.

In this study, nine Chinese chestnut varieties were planted in the same farm and grew under the same conditions. Starches were isolated from fresh kernels of mature nuts, and their physicochemical properties were systematically investigated using multiple physicochemical techniques, including X-ray powder diffraction (XRD), attenuated total reflectance Fourier transform infrared (ATR-FTIR), small-angle X-ray scattering (SAXS), thermogravimetry analysis (TGA), differential scanning calorimeter (DSC), rapid visco analyzer (RVA), and some routine physicochemical measuring methods. Our objective was to investigate and compare the physicochemical properties of starches from different varieties under the same growing conditions. This study may provide some information for the quality breeding of Chinese chestnut varieties and their utilization in food and non-food industries.

\section{Results and Discussion}

\subsection{Weight and Starch Content of Kernels}

The fresh nuts of nine Chinese chestnut varieties are presented in Figure 1. They had significantly different colors and sizes. The weight of nuts and kernels were measured (Table 1). Different varieties had significantly different fresh nut weights ranging from 6.4 to $12.2 \mathrm{~g} / \mathrm{nut}$, fresh kernel weights ranging from 5.5 to $10.5 \mathrm{~g} / \mathrm{kernel}$, and dry kernel weights ranging from 2.5 to $5.6 \mathrm{~g} / \mathrm{kernel}$, with the highest for the Dahongpao and the lowest for the variety 3113. The starch content in dry kernel ranged from 42.7 to $49.3 \%$ (Table 1). The starch content in the present study is in the ranges reported by Liu et al. [16], which showed that four varieties of Chinese chestnut had starch contents from 42.4 to $53.8 \%$. However, Hao et al. [18] reported that the starch contents ranged from 58.3 to $63.6 \%$ 
among six Chinese chestnut varieties. The obviously high starch contents in their report might result from the different measuring methods in starch content, variety genotype backgrounds, and plant growing conditions. In addition, the $71.4 \%$ and $78.8 \%$ starch contents have also been reported in C. sativa varieties $[15,17]$. The starch contents are influenced by plant species though they are in the same genus. The high starch content indicates that chestnuts have potential as starch sources for food and non-food applications. Therefore, the information for starch content provides a scientific basis to develop chestnut varieties.
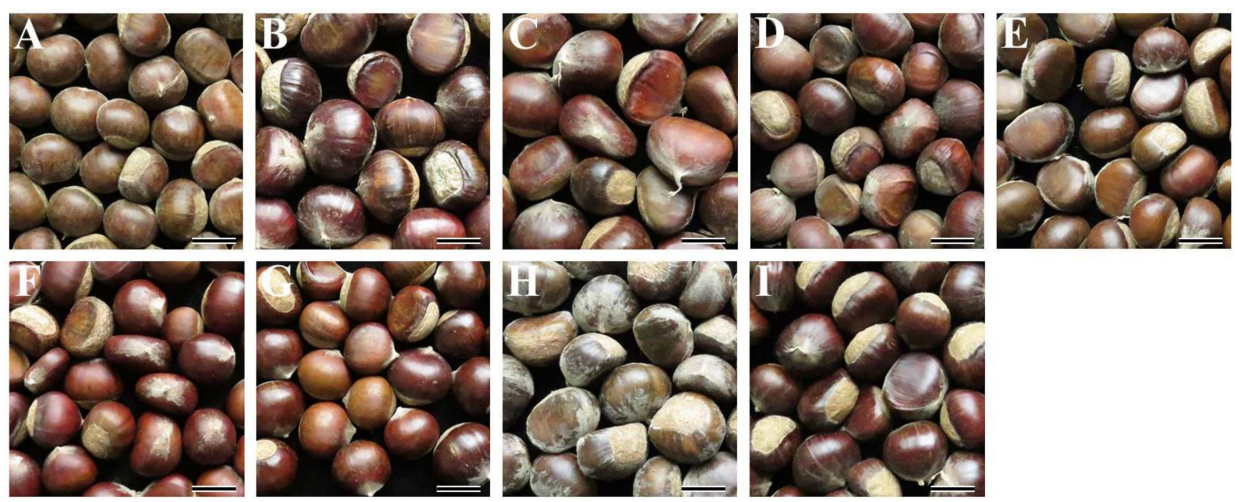

Figure 1. Photographs of nuts from Chinese chestnut variety 3113 (A), Benlizi (B), Dahongpao (C), Erqingzao (D), Heishanzhai 7 (E), Mi 5 (F), Mi 6 (G), Yangguang (H), and Yanshanhong (I). Scale bar = $20 \mathrm{~mm}$.

Table 1. Nut and kernel weights and starch content in kernel.

\begin{tabular}{|c|c|c|c|c|}
\hline \multirow[b]{2}{*}{ Varieties } & \multirow[b]{2}{*}{ Fresh Nut Weight (g/nut) } & \multirow[b]{2}{*}{ Fresh Kernel Weight (g/kernel) } & \multicolumn{2}{|c|}{ Dry Kernel } \\
\hline & & & $\begin{array}{l}\text { Kernel Weight } \\
\text { (g/kernel) }\end{array}$ & $\begin{array}{c}\text { Starch Content } \\
(\%)\end{array}$ \\
\hline 3113 & $6.4 \pm 0.1^{\mathrm{a}}$ & $5.5 \pm 0.1^{\mathrm{a}}$ & $2.51 \pm 0.03^{a}$ & $43.3 \pm 0.2^{\mathrm{a}, \mathrm{b}}$ \\
\hline Benlizi & $11.9 \pm 0.5^{\mathrm{e}}$ & $9.9 \pm 0.4 \mathrm{~d}, \mathrm{e}$ & $4.95 \pm 0.20^{\mathrm{d}}$ & $46.7 \pm 1.0^{\mathrm{b}, \mathrm{c}}$ \\
\hline Dahongpao & $12.2 \pm 0.7^{\mathrm{e}}$ & $10.5 \pm 0.5^{\mathrm{e}}$ & $5.61 \pm 0.29^{\mathrm{e}}$ & $49.2 \pm 0.9^{c}$ \\
\hline Erqingzao & $6.7 \pm 0.5^{\mathrm{a}, \mathrm{b}}$ & $5.5 \pm 0.4^{\mathrm{a}}$ & $3.29 \pm 0.22^{b}$ & $42.7 \pm 1.0^{\mathrm{a}}$ \\
\hline Heishanzhai 7 & $7.0 \pm 0.2^{\mathrm{a}, \mathrm{b}, \mathrm{c}}$ & $6.1 \pm 0.2^{\mathrm{a}, \mathrm{b}}$ & $2.98 \pm 0.11^{b}$ & $47.6 \pm 1.5^{c}$ \\
\hline Mi 5 & $7.9 \pm 0.1^{\mathrm{c}}$ & $6.8 \pm 0.1^{b}$ & $3.90 \pm 0.04^{c}$ & $43.6 \pm 1.2^{\mathrm{a}, \mathrm{b}}$ \\
\hline Mi 6 & $7.7 \pm 0.6^{\mathrm{b}, \mathrm{c}}$ & $6.6 \pm 0.5^{b}$ & $3.16 \pm 0.22^{b}$ & $46.4 \pm 1.0^{\mathrm{a}, \mathrm{b}, \mathrm{c}}$ \\
\hline Yangguang & $10.6 \pm 0.1^{\mathrm{d}}$ & $9.2 \pm 0.2^{\mathrm{c}, \mathrm{d}}$ & $4.29 \pm 0.08^{c}$ & $49.3 \pm 1.2^{c}$ \\
\hline Yanshanhong & $10.2 \pm 0.3^{\mathrm{d}}$ & $8.7 \pm 0.3^{c}$ & $4.78 \pm 0.17^{\mathrm{d}}$ & $43.1 \pm 0.6^{\mathrm{a}, \mathrm{b}}$ \\
\hline Mean $\pm \mathrm{SD}$ & $9.0 \pm 2.3$ & $7.6 \pm 1.9$ & $3.94 \pm 1.04$ & $45.8 \pm 2.7$ \\
\hline Sig. & 0.160 & 0.205 & 0.802 & 0.137 \\
\hline
\end{tabular}

Data are means \pm standard deviations, $n=3$. Values in the same column with different superscript letters (a-e) are significantly different $(p<0.05)$. Mean \pm SD: the average value and standard deviation of nine samples. Sig.: The significance of normal distribution of nine samples by Shapiro-Wilk test.

\subsection{Morphology and Size Distribution of Starch Granule}

The Figure 2A-C shows the morphology of starch granules from Chinese chestnut variety 3113 under normal light microscope, polarized light microscope, and scanning electron microscope, and the starches from the other varieties had similar morphologies to the 3113 starch (data not shown). The nine chestnut starches all exhibited round, oval, ellipsoidal, and irregular polygonal in shapes with a central hilum and smooth surface. Similar morphologies were also reported for the chestnut starches $[18,29]$. The granule size was analyzed with a laser diffraction particle size analyzer. The nine chestnut starches all had bimodal size distributions with small granules from 0.5 to $1.5 \mu \mathrm{m}$ and large granules from 1.5 to $25 \mu \mathrm{m}$ (data not shown). The bimodal size distribution is reported in other chestnut starches [30]. The volume percentage of small granule starch ranged from $9.76 \%$ for Mi 6 to 11.84\% for Mi 5 among the nine Chinese chestnut varieties (Table 2). The bimodal size distribution of large and small granules is characteristic of wheat and barley endosperm starches. The large granules form at the early stage of endosperm development, and account for more than 
$70 \%$ of the total starch weight but less than $10 \%$ of the granules by number. The small granules form at the middle and late stages of endosperm development, and account for over $90 \%$ of the granules by number but less than $30 \%$ of the total starch by weight $[31,32]$. The large starch granules have more surface pores and internal channels, higher amylose content, and lower swelling power and hydrolysis rate than the small starch granules [32,33]. Starches with predominantly small granules have potential uses as a fat replacement, fine printing paper, plastic sheet, and a carrier material in cosmetics [31]. The proportion of large and small granules differed among different chestnut varieties, which might influence the physicochemical properties of starches. The granule sizes are presented in Table 2. The nine Chinese chestnut starches had granule sizes $\mathrm{d}(0.1)$ from 1.7 to $2.3 \mu \mathrm{m}, \mathrm{d}(0.5)$ from 6.9 to $7.9 \mu \mathrm{m}, \mathrm{d}(0.9)$ from 12.2 to $14.0 \mu \mathrm{m}$, and $\mathrm{D}[4,3]$ from 7.2 to $8.2 \mu \mathrm{m}$. Similar granule size was also reported in six Chinese chestnut starches [18].
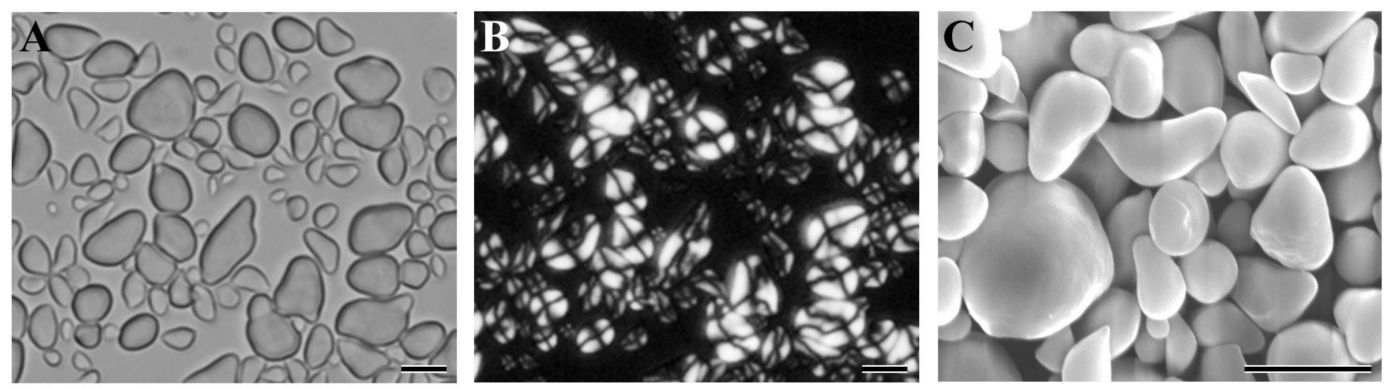

Figure 2. The morphology of starch granules from variety 3113 under normal light microscope (A), polarized light microscope (B), and scanning electron microscope (C). Scale bar $=10 \mu \mathrm{m}$.

Table 2. Volume percentage of small starch granules and starch granule size distribution.

\begin{tabular}{cccccc}
\hline Varieties & Small Granule (\%) & $\mathbf{d}(\mathbf{0 . 1})(\boldsymbol{\mu m})$ & $\mathbf{d}(\mathbf{0 . 5})(\boldsymbol{\mu m})$ & $\mathbf{d}(\mathbf{0 . 9})(\boldsymbol{\mu m})$ & $\mathbf{D}[\mathbf{4 , 3}(\boldsymbol{\mu m})$ \\
\hline 3113 & $11.04 \pm 0.05^{\mathrm{f}}$ & $1.934 \pm 0.012^{\mathrm{c}}$ & $7.431 \pm 0.004^{\mathrm{e}}$ & $13.620 \pm 0.008^{\mathrm{f}}$ & $7.819 \pm 0.003^{\mathrm{f}}$ \\
Benlizi & $10.24 \pm 0.04^{\mathrm{b}}$ & $2.156 \pm 0.015^{\mathrm{f}}$ & $7.706 \pm 0.001^{\mathrm{g}}$ & $13.855 \pm 0.004^{\mathrm{h}}$ & $8.048 \pm 0.001^{\mathrm{g}}$ \\
Dahongpao & $10.70 \pm 0.04^{\mathrm{e}}$ & $1.988 \pm 0.011^{\mathrm{d}}$ & $7.291 \pm 0.001^{\mathrm{d}}$ & $13.073 \pm 0.004^{\mathrm{c}}$ & $7.607 \pm 0.001^{\mathrm{d}}$ \\
Erqingzao & $11.27 \pm 0.06^{\mathrm{g}}$ & $1.776 \pm 0.016^{\mathrm{b}}$ & $6.901 \pm 0.002^{\mathrm{a}}$ & $12.241 \pm 0.001^{\mathrm{a}}$ & $7.170 \pm 0.003^{\mathrm{a}}$ \\
Heishanzhai 7 & $10.60 \pm 0.03^{\mathrm{d}}$ & $2.264 \pm 0.013^{\mathrm{g}}$ & $7.911 \pm 0.001^{\mathrm{i}}$ & $14.047 \pm 0.003^{\mathrm{i}}$ & $8.226 \pm 0.001^{\mathrm{i}}$ \\
Mi 5 & $11.84 \pm 0.05^{\mathrm{h}}$ & $1.778 \pm 0.009^{\mathrm{b}}$ & $7.148 \pm 0.003^{\mathrm{c}}$ & $13.127 \pm 0.008^{\mathrm{d}}$ & $7.496 \pm 0.002^{\mathrm{c}}$ \\
Mi 6 & $9.76 \pm 0.03^{\mathrm{a}}$ & $2.337 \pm 0.014^{\mathrm{h}}$ & $7.764 \pm 0.001^{\mathrm{h}}$ & $13.835 \pm 0.002^{\mathrm{g}}$ & $8.099 \pm 0.001^{\mathrm{h}}$ \\
Yangguang & $10.43 \pm 0.04^{\mathrm{c}}$ & $2.091 \pm 0.013^{\mathrm{e}}$ & $7.506 \pm 0.002^{\mathrm{f}}$ & $13.350 \pm 0.005^{\mathrm{e}}$ & $7.807 \pm 0.001^{\mathrm{e}}$ \\
Yanshanhong & $11.29 \pm 0.02^{\mathrm{g}}$ & $1.737 \pm 0.001^{\mathrm{a}}$ & $6.954 \pm 0.017^{\mathrm{b}}$ & $12.983 \pm 0.017^{\mathrm{b}}$ & $7.329 \pm 0.015^{\mathrm{b}}$ \\
Mean \pm SD & $10.80 \pm 0.63$ & $2.007 \pm 0.220$ & $7.401 \pm 0.358$ & $13.348 \pm 0.563$ & $7.733 \pm 0.361$ \\
Sig. & 0.993 & 0.485 & 0.744 & 0.564 & 0.819 \\
\hline
\end{tabular}

The $\mathrm{d}(0.1), \mathrm{d}(0.5)$, and $\mathrm{d}(0.9)$ are the granule diameter at which $10 \%, 50 \%$, and $90 \%$ of all the granules by volume are smaller, respectively. The $\mathrm{D}[4,3]$ is the volume-weighted mean diameter. Data are means \pm standard deviations, $n=3$. Values in the same column with different superscript letters $(\mathrm{a}-\mathrm{i})$ are significantly different $(p<0.05)$. Mean \pm SD: the average value and standard deviation of nine samples. Sig.: The significance of normal distribution of nine samples by Shapiro-Wilk test.

\subsection{Iodine Absorption Spectrum and Amylose Content of Starch}

The iodine absorption spectra of nine starches were determined, their derived parameters including maximum absorption wavelength, iodine blue value, and absorbance ratio of OD 620 to OD 550 (OD620/550) had no significant differences among nine starches (data not shown), but the apparent amylose contents ranged from 23.8 to $27.3 \%$ (Table 3). Some literatures report the amylose contents ranging from 21.2 to $29.8 \%$ in Chinese chestnut starches [16,18], from 21.5 to $32.8 \%$ in C. sativa starches $[15,20,21]$. The amylose is a major component of starch and plays an important role in structural and functional properties. Though the differences in measuring methods between different studies made their data hard to compare, the variations in amylose contents were detected among different varieties in the present study. The different amylose contents of nine Chinese chestnut starches might result from their different genotype backgrounds. 
Table 3. Apparent amylose content, relative intensity, ordered degree, and lamellar structure parameters of starch.

\begin{tabular}{cccccc}
\hline Varieties & AAC (\%) & RC (\%) & OD & \multicolumn{2}{c}{ Lamellar Structure Parameters } \\
\cline { 5 - 6 } & & & & PI (counts) & D (nm) \\
\hline 3113 & $26.1 \pm 0.5^{\mathrm{b}, \mathrm{c}}$ & $20.0 \pm 0.8^{\mathrm{a}, \mathrm{b}}$ & $0.61 \pm 0.02^{\mathrm{a}}$ & $143 \pm 8^{\mathrm{a}, \mathrm{b}}$ & $9.46 \pm 0.09^{\mathrm{a}}$ \\
Benlizi & $24.2 \pm 0.7^{\mathrm{a}, \mathrm{b}}$ & $18.5 \pm 0.5^{\mathrm{a}}$ & $0.63 \pm 0.02^{\mathrm{a}}$ & $132 \pm 6^{\mathrm{a}, \mathrm{b}}$ & $9.49^{\mathrm{a}} \pm 0.00^{\mathrm{a}}$ \\
Dahongpao & $23.8 \pm 1.1^{\mathrm{a}}$ & $20.7 \pm 0.8^{\mathrm{a}, \mathrm{b}}$ & $0.63 \pm 0.02^{\mathrm{a}}$ & $136 \pm 16^{\mathrm{a}, \mathrm{b}}$ & $9.38 \pm 0.01^{\mathrm{a}}$ \\
Erqingzao & $24.5 \pm 0.9^{\mathrm{a}, \mathrm{b}}$ & $20.4 \pm 0.5^{\mathrm{a}, \mathrm{b}}$ & $0.62 \pm 0.02^{\mathrm{a}}$ & $150 \pm 3^{\mathrm{b}}$ & $9.44 \pm 0.04^{\mathrm{a}}$ \\
Heishanzhai 7 & $23.8 \pm 0.9^{\mathrm{a}}$ & $21.2 \pm 0.9^{\mathrm{b}}$ & $0.64 \pm 0.02^{\mathrm{a}}$ & $146 \pm 7^{\mathrm{a}, \mathrm{b}}$ & $9.30 \pm 0.01^{\mathrm{a}}$ \\
Mi 5 & $26.2 \pm 1.1^{\mathrm{b}, \mathrm{c}}$ & $20.0 \pm 1.4^{\mathrm{a}, \mathrm{b}}$ & $0.63 \pm 0.01^{\mathrm{a}}$ & $133 \pm 8^{\mathrm{a}, \mathrm{b}}$ & $9.27 \pm 0.03^{\mathrm{a}}$ \\
Mi 6 & $23.8 \pm 0.9^{\mathrm{a}}$ & $20.7 \pm 0.4^{\mathrm{a}, \mathrm{b}}$ & $0.65 \pm 0.02^{\mathrm{a}}$ & $120 \pm 4^{\mathrm{a}}$ & $9.40 \pm 0.01^{\mathrm{a}}$ \\
Yangguang & $24.6 \pm 0.6^{\mathrm{a}, \mathrm{b}}$ & $21.2 \pm 0.9^{\mathrm{b}}$ & $0.64 \pm 0.02^{\mathrm{a}}$ & $130 \pm 1^{\mathrm{a}, \mathrm{b}}$ & $9.33 \pm 0.14^{\mathrm{a}}$ \\
Yanshanhong & $27.3 \pm 0.5^{\mathrm{c}}$ & $20.7 \pm 0.6^{\mathrm{a}, \mathrm{b}}$ & $0.64 \pm 0.02^{\mathrm{a}}$ & $119 \pm 3^{\mathrm{a}}$ & $9.33 \pm 0.01^{\mathrm{a}}$ \\
Mean \pm SD & $24.9 \pm 1.3$ & $20.4 \pm 0.8$ & $0.63 \pm 0.01$ & $134 \pm 11$ & $9.38 \pm 0.08$ \\
Sig. & 0.055 & 0.059 & 0.586 & 0.674 & 0.780 \\
\hline
\end{tabular}

AAC: apparent amylose content; RC: relative crystallinity; OD: ordered degree; PI: lamellar peak intensity; D: lamellar distance. Data are means \pm standard deviations, $n=3$ for AAC and $=2$ for RC, OD, and lamellar structure parameters. Values in the same column with different superscript letters $(\mathrm{a}-\mathrm{c})$ are significantly different $(p<0.05)$. Mean \pm SD: the average value and standard deviation of nine samples. Sig.: The significance of normal distribution of nine samples by Shapiro-Wilk test.

\subsection{Crystalline Structure of Starch}

The XRD patterns of nine Chinese chestnut starches are shown in Figure 3. According to XRD patterns, plant starches are classified into A-, B- and C-type [34]. The nine Chinese chestnut starches exhibited strong diffraction peak at about $17^{\circ} 2 \theta$ and some small peaks at about $5.6^{\circ}, 15^{\circ}, 20^{\circ}$, and $23^{\circ}$ $2 \theta$ (Figure 3). The diffraction peak at about $5.6^{\circ} 2 \theta$ is a characteristic peak of B-type crystallinity, that at $23^{\circ} 2 \theta$ is a characteristic peak of A-type crystallinity, and that at $20^{\circ} 2 \theta$ is an amylose-lipid complex diffraction peak. The XRD patterns showed that the nine Chinese chestnut starches contained both A- and B-type crystallinity and belonged to C-type starch. Though their XRD patterns were very similar, two shoulder peaks were visible in Heishanzhai 7, Mi 5, and Mi 6 starches, indicating that the three starches contained a high proportion of B-type crystallinity and were $C_{B}$-type starches, and the other starches had typical C-type starches (Figure 3). Some literatures report that starch from Chinese chestnut shows C-type [16], and starch from C. sativa exhibits B-type $[19,20]$, and starch from C. crenata has $C_{B}$-type [29]. The relative crystallinities ranged from 18.5 to $21.2 \%$ among nine Chinese chestnut starches (Table 3).

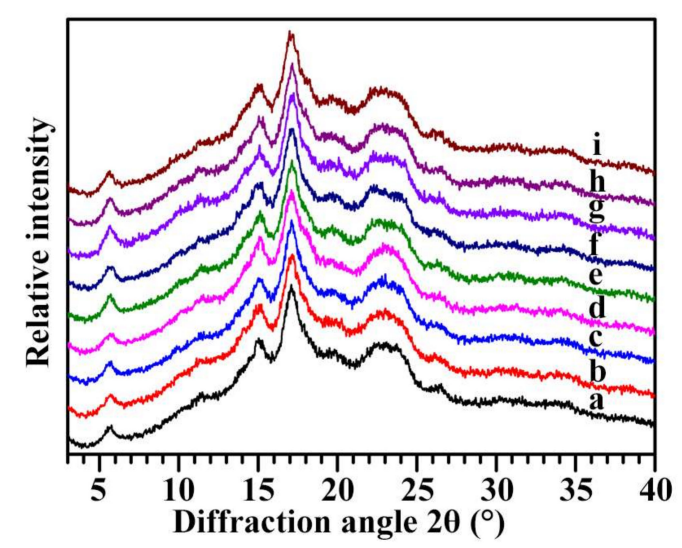

Figure 3. XRD patterns of starches from variety 3113 (a), Benlizi (b), Dahongpao (c), Erqingzao (d), Heishanzhai 7 (e), Mi 5 (f), Mi 6 (g), Yangguang (h), and Yanshanhong (i). 


\subsection{Short-Ranged Ordered Structure of Starch}

The ATR-FTIR spectra of nine Chinese chestnut starches are shown in Figure 4. The ATR-FTIR spectrum is sensitive to the short-range ordered structure, defined as the double-helical order, as opposed to the long-range ordered structure related to the packing of double helices $[35,36]$. The FTIR spectrum of starch shows bands at $1150-1100 \mathrm{~cm}^{-1}$ (C-O, C-C, and C-O-H stretching) and $1100-900 \mathrm{~cm}^{-1}$ (C-O-H bending). The bands in the region $1100-900 \mathrm{~cm}^{-1}$ have been shown to be sensitive to changes in starch structure, especially the bands at 1045 and $1022 \mathrm{~cm}^{-1}$. The band at $1045 \mathrm{~cm}^{-1}$ is linked with order/crystalline region, and that at $1022 \mathrm{~cm}^{-1}$ arises as a result of absorption by stretching modes in amorphous structure [36]. The absorbance ratio of 1045/1022 $\mathrm{cm}^{-1}$ can reflect the ordered degree in the starch [36]. The nine Chinese chestnut starches had similar ATR-FTIR spectra in the region 1200-900 $\mathrm{cm}^{-1}$ (Figure 4) and their absorbance ratios of 1045/1022 $\mathrm{cm}^{-1}$ ranged from 0.61 to 0.65 (Table 3).

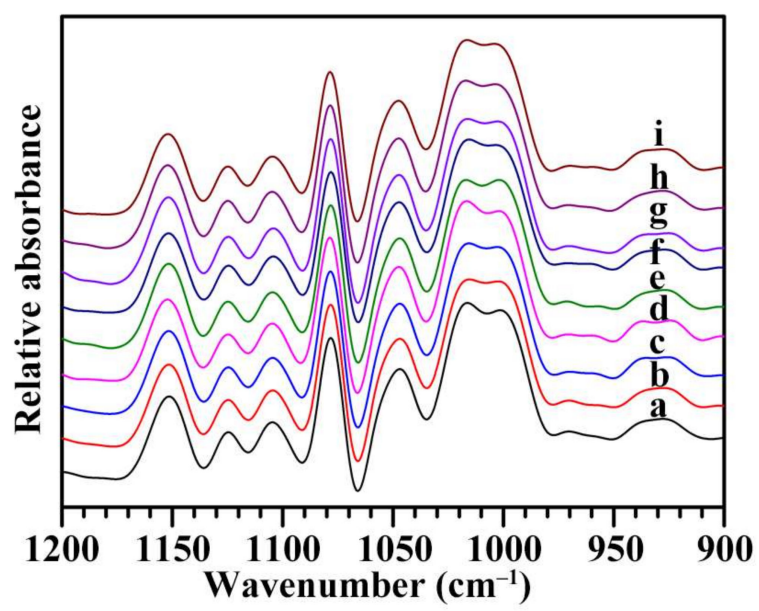

Figure 4. ATR-FTIR spectra of starches from variety 3113 (a), Benlizi (b), Dahongpao (c), Erqingzao (d), Heishanzhai 7 (e), Mi 5 (f), Mi 6 (g), Yangguang (h), and Yanshanhong (i).

\subsection{Lamellar Structure of Starch}

The semi-crystalline growth rings formed by alternating amorphous and crystalline regions can be detected by SAXS. The SAXS patterns of nine Chinese chestnut starches are shown in Figure 5. All spectra were normalized to equal intensity at high $\mathrm{q}\left(0.2 \AA^{-1}\right)$ to account for variations in sample concentration, leading to the spectra being at the same relative scale and directly comparable. The main scattering peak at scattering vector of about $0.066 \AA^{-1}$ is thought to arise from the periodic arrangement of alternating crystalline and amorphous lamellae of amylopectin and corresponds to lamellar repeat distance or Bragg spacing [37]. The peak position reflects the size of lamellae and may differ for starch originated from different plants, while the peak intensity reflects the electron density difference between the crystalline and amorphous regions of the lamellae. The lamellar repeat distance (D) can be calculated from the peak position (Smax) according to $\mathrm{D}=2 \pi / \mathrm{Smax}[37,38]$. The nine Chinese chestnut starches had lamellar peak intensity from 119 to 150 and lamellar distance from 9.27 to $9.49 \mathrm{~nm}$ (Table 3). 


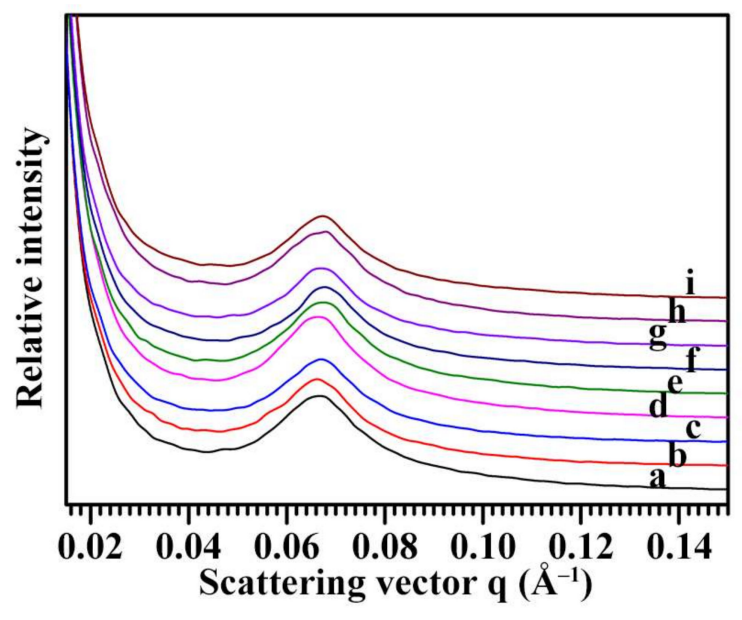

Figure 5. SAXS spectra of starches from variety 3113 (a), Benlizi (b), Dahongpao (c), Erqingzao (d), Heishanzhai 7 (e), Mi 5 (f), Mi 6 (g), Yangguang (h), and Yanshanhong (i).

\subsection{Thermal Properties of Starch}

The thermal properties of nine Chinese chestnut starches were measured with a DSC. The DSC thermographs are presented in Figure 6, and thermal parameters are shown in Table 4. Though the gelatinization enthalpy was similar, but gelatinization temperatures had some differences among nine starches. The gelatinization onset, peak, and conclusion temperatures ranged from 60.4 to $63.9^{\circ} \mathrm{C}$, from 64.8 to $68.3{ }^{\circ} \mathrm{C}$, and from 70.5 to $74.5{ }^{\circ} \mathrm{C}$, respectively. Similar gelatinization temperatures are reported in starches from Chinese chestnuts cultivated in three different regions of Korea [39]. The gelatinization onset temperature $\left(57.1^{\circ} \mathrm{C}\right)$, peak temperature $\left(61.9^{\circ} \mathrm{C}\right)$, and conclusion temperature $\left(67.9^{\circ} \mathrm{C}\right)$ in C. sativa starch [20] are lower than those in Chinese chestnut starches. Liu et al. [16] reported that the gelatinization onset, peak, and conclusion temperatures range from 59.5 to $61.2^{\circ} \mathrm{C}$, from 63.7 to $65.3^{\circ} \mathrm{C}$, and from 68.5 to $70.6^{\circ} \mathrm{C}$, respectively, among four Chinese chestnut varieties, but their gelatinization enthalpies are similar. In the study of Liu et al. [16], the starch-to-water ratio is 1:2. In the present study, the starch-to-water ratio is 1:3. The different water contents influence the thermal parameters [40].

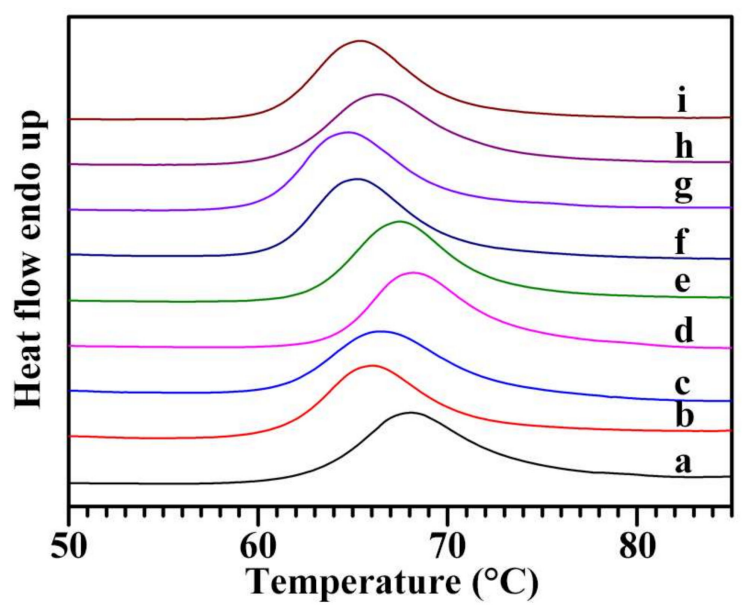

Figure 6. DSC thermographs of starches from variety 3113 (a), Benlizi (b), Dahongpao (c), Erqingzao (d), Heishanzhai 7 (e), Mi 5 (f), Mi 6 (g), Yangguang (h), and Yanshanhong (i). 
Table 4. Thermal parameters of starch.

\begin{tabular}{|c|c|c|c|c|c|}
\hline Varieties & To $\left({ }^{\circ} \mathrm{C}\right)$ & $\operatorname{Tp}\left({ }^{\circ} \mathrm{C}\right)$ & Tc $\left({ }^{\circ} \mathrm{C}\right)$ & $\Delta \mathrm{T}\left({ }^{\circ} \mathrm{C}\right)$ & $\Delta \mathrm{H}(\mathrm{J} / \mathrm{g})$ \\
\hline 3113 & $62.7 \pm 0.3^{c}$ & $68.1 \pm 0.1^{\mathrm{f}}$ & $74.5 \pm 0.3^{\mathrm{e}}$ & $11.8 \pm 0.0^{\mathrm{d}, \mathrm{e}}$ & $13.1 \pm 0.1^{\mathrm{a}}$ \\
\hline Benlizi & $61.4 \pm 0.1^{b}$ & $66.1 \pm 0.1^{c}$ & $72.0 \pm 0.1^{\mathrm{c}}$ & $10.6 \pm 0.0^{c}$ & $12.8 \pm 0.2^{\mathrm{a}}$ \\
\hline Dahongpao & $61.4 \pm 0.2^{b}$ & $66.7 \pm 0.2^{d}$ & $73.3 \pm 0.0^{\mathrm{d}}$ & $12.0 \pm 0.2^{\mathrm{e}}$ & $13.1 \pm 0.1^{\mathrm{a}}$ \\
\hline Erqingzao & $63.9 \pm 0.1^{d}$ & $68.3 \pm 0.1^{\mathrm{f}}$ & $74.3 \pm 0.0^{\mathrm{e}}$ & $10.5 \pm 0.1^{b, c}$ & $13.6 \pm 0.1^{\mathrm{a}}$ \\
\hline Heishanzhai 7 & $62.9 \pm 0.1^{\mathrm{c}}$ & $67.6 \pm 0.1^{\mathrm{e}}$ & $73.2 \pm 0.2^{\mathrm{d}}$ & $10.3 \pm 0.1^{\mathrm{a}, \mathrm{b}}$ & $12.8 \pm 0.2^{\mathrm{a}}$ \\
\hline Mi 5 & $60.9 \pm 0.0^{b}$ & $65.2 \pm 0.0^{b}$ & $70.9 \pm 0.0^{\mathrm{a}, \mathrm{b}}$ & $10.0 \pm 0.0^{\mathrm{a}}$ & $13.4 \pm 0.2^{\mathrm{a}}$ \\
\hline Mi 6 & $60.4 \pm 0.0^{\mathrm{a}}$ & $64.8 \pm 0.1^{\mathrm{a}}$ & $70.5 \pm 0.1^{a}$ & $10.1 \pm 0.1^{\mathrm{a}}$ & $13.3 \pm 0.4^{\mathrm{a}}$ \\
\hline Yangguang & $61.3 \pm 0.1^{b}$ & $66.4 \pm 0.1^{d}$ & $72.9 \pm 0.2^{d}$ & $11.6 \pm 0.1^{\mathrm{d}}$ & $12.8 \pm 0.4^{\mathrm{a}}$ \\
\hline Yanshanhong & $60.9 \pm 0.1^{b}$ & $65.4 \pm 0.1^{b}$ & $71.1 \pm 0.1^{b}$ & $10.2 \pm 0.0^{\mathrm{a}, \mathrm{b}}$ & $13.2 \pm 0.1^{\mathrm{a}}$ \\
\hline Mean \pm SD & $61.8 \pm 1.1$ & $66.5 \pm 1.3$ & $72.5 \pm 1.5$ & $10.8 \pm 0.8$ & $13.1 \pm 0.3$ \\
\hline Sig. & 0.226 & 0.564 & 0.467 & 0.053 & 0.345 \\
\hline
\end{tabular}

$\mathrm{To}, \mathrm{Tp}$, and Tc: gelatinization onset, peak, and conclusion temperature, respectively; $\Delta \mathrm{T}$ and $\Delta \mathrm{H}$ : gelatinization temperature range (Tc-To) and enthalpy, respectively. Data are means \pm standard deviations, $n=3$. Values in the same column with different superscript letters $(\mathrm{a}-\mathrm{e})$ are significantly different $(p<0.05)$. Mean \pm SD: the average value and standard deviation of nine samples. Sig.: The significance of normal distribution of nine samples by Shapiro-Wilk test.

\subsection{Pasting Properties of Starch}

The pasting properties of starch are important functional properties and determine the quality and utilization of starch in food industry. The pasting properties of starch have been analyzed in some papers [41,42]. The pasting properties of nine chestnut starches were measured using an RVA. The pasting profiles and parameters are presented in Figure 7 and Table 5, respectively. The peak, hot, breakdown, final, and setback viscosities ranged from 5524 to $6505 \mathrm{mPa}$ s, from 3042 to $3616 \mathrm{mPa}$ s, from 2205 to $2954 \mathrm{mPa}$ s, from 4378 to $4942 \mathrm{mPa}$ s, and from 1326 to $1788 \mathrm{mPa}$ s, respectively. Liu et al. [16] reported that the peak, hot, breakdown, final, and setback viscosities range from 2658 to $3301 \mathrm{cP}$, from 2086 to $2434 \mathrm{cP}$, from 541 to $925 \mathrm{cP}$, from 3802 to $4451 \mathrm{cP}$, and from 1685 to $2017 \mathrm{cp}$, respectively, among four Chinese chestnut varieties. Peak viscosity reflects the bind ability of starch and water, and final viscosity reflects the stability of swelling granule. Breakdown viscosity is negatively correlated to the pasting resistance of starch to heat, and setback viscosity indicates the tendency of starch paste to retrogradation [43]. The pasting properties of starches are affected by granule morphology, size, amylose content, crystalline structure, and swelling power [44]. In comparison with the results of Liu et al. [16], the chestnut starches in the present study had significantly higher peak, hot, and breakdown viscosities. Though the differences in experimental conditions between different studies make their data hard to compare, the variations in pasting properties were detected among different varieties in the present study.

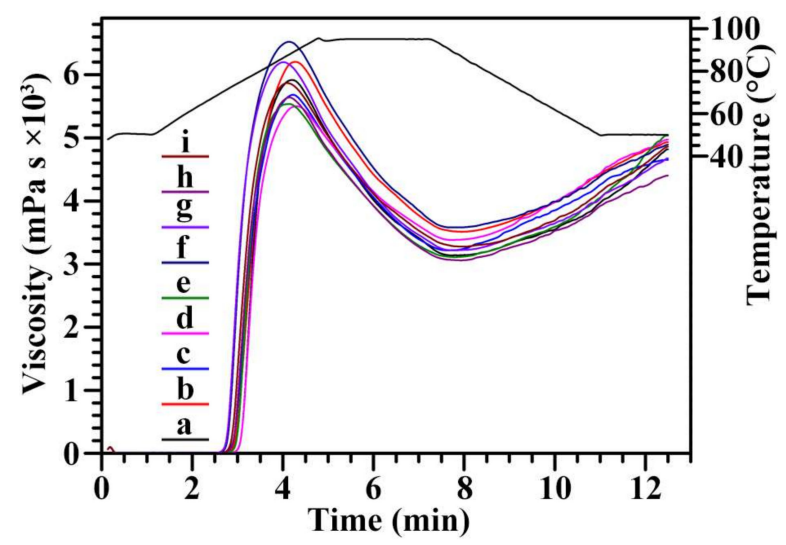

Figure 7. RVA profiles of starches from variety 3113 (a), Benlizi (b), Dahongpao (c), Erqingzao (d), Heishanzhai 7 (e), Mi 5 (f), Mi 6 (g), Yangguang (h), and Yanshanhong (i). 
Table 5. Pasting parameters of starch.

\begin{tabular}{cccccc}
\hline Varieties & PV (mPa s) & HV (mPa s) & BV (mPa s) & FV (mPa s) & SV (mPa s) \\
\hline 3113 & $5866 \pm 49^{\mathrm{c}}$ & $3104 \pm 31^{\mathrm{a}, \mathrm{b}}$ & $2762 \pm 18^{\mathrm{f}}$ & $4745 \pm 65^{\mathrm{b}, \mathrm{c}}$ & $1641 \pm 37^{\mathrm{c}}$ \\
Benlizi & $6219 \pm 38^{\mathrm{d}}$ & $3487 \pm 74^{\mathrm{d}}$ & $2732 \pm 48^{\mathrm{e}, \mathrm{f}}$ & $4954 \pm 62^{\mathrm{d}}$ & $1467 \pm 41^{\mathrm{d}}$ \\
Dahongpao & $5722 \pm 51^{\mathrm{b}}$ & $3260 \pm 40^{\mathrm{b}, \mathrm{c}}$ & $2462 \pm 56^{\mathrm{b}, \mathrm{c}}$ & $4650 \pm 35^{\mathrm{b}}$ & $1390 \pm 42^{\mathrm{a}, \mathrm{b}}$ \\
Erqingzao & $5524 \pm 21^{\mathrm{a}}$ & $3319 \pm 64^{\mathrm{c}}$ & $2205 \pm 84^{\mathrm{a}}$ & $4942 \pm 27^{\mathrm{d}}$ & $1623 \pm 50^{\mathrm{c}}$ \\
Heishanzhai 7 & $5527 \pm 23^{\mathrm{a}}$ & $3125 \pm 59^{\mathrm{a}, \mathrm{b}}$ & $2402 \pm 46^{\mathrm{b}}$ & $4913 \pm 35^{\mathrm{d}}$ & $1788 \pm 79^{\mathrm{d}}$ \\
Mi 5 & $6505 \pm 41^{\mathrm{e}}$ & $3616 \pm 58^{\mathrm{d}}$ & $2889 \pm 51^{\mathrm{g}}$ & $4942 \pm 50^{\mathrm{d}}$ & $1326 \pm 27^{\mathrm{a}}$ \\
Mi 6 & $6192 \pm 23^{\mathrm{d}}$ & $3238 \pm 23^{\mathrm{b}, \mathrm{c}}$ & $2954 \pm 29^{\mathrm{g}}$ & $4663 \pm 32^{\mathrm{b}}$ & $1425 \pm 53^{\mathrm{a}, \mathrm{b}}$ \\
Yangguang & $5609 \pm 91^{\mathrm{a}}$ & $3042 \pm 98^{\mathrm{a}}$ & $2567 \pm 22^{\mathrm{c}, \mathrm{d}}$ & $4378 \pm 68^{\mathrm{a}}$ & $1336 \pm 33^{\mathrm{a}}$ \\
Yanshanhong & $5860 \pm 27^{\mathrm{c}}$ & $3220 \pm 67^{\mathrm{b}, \mathrm{c}}$ & $2640 \pm 45^{\mathrm{d}, \mathrm{e}}$ & $4829 \pm 34^{\mathrm{c}, \mathrm{d}}$ & $1609 \pm 33^{\mathrm{c}}$ \\
Mean \pm SD & $5892 \pm 345$ & $3268 \pm 185$ & $2624 \pm 241$ & $4780 \pm 192$ & $1512 \pm 160$ \\
Sig. & 0.320 & 0.486 & 0.954 & 0.098 & 0.417 \\
\hline
\end{tabular}

PV: peak viscosity; HV: hot viscosity; FV: final viscosity; BV: breakdown viscosity (PV-HV); SV: setback viscosity $(\mathrm{FV}-\mathrm{HV})$. Data are means \pm standard deviations, $n=3$. Values in the same column with different superscript letters $(\mathrm{a}-\mathrm{g})$ are significantly different $(p<0.05)$. Mean \pm SD: the average value and standard deviation of nine samples. Sig.: The significance of normal distribution of nine samples by Shapiro-Wilk test.

\subsection{Thermal Stability of Starch}

The TGA curves are usually used to evaluate the differences in thermal stability of starch caused by structural distinctions. The TGA curves of nine starches are presented in Figure 8A. Two well-defined shifts were clearly detected. There are two crystal structures in starch, one is from (between) the ordered packing including starch molecular chains and water molecules, and the other is from the ordered packing between starch molecular chains by the interaction of hydrogen bonds. The first weight loss corresponds with the destruction of the starch-water structure, while the second is the decomposition of starch and reflects the destruction of the starch-starch structure [45]. The derivative thermogravimetric (DTG) curves of starches are presented in Figure 8B and show that the decomposition temperature occurred from 309 to $311^{\circ} \mathrm{C}$. Similar TGA and DTG curves among nine chestnut starches showed that their thermal stabilities had no difference.

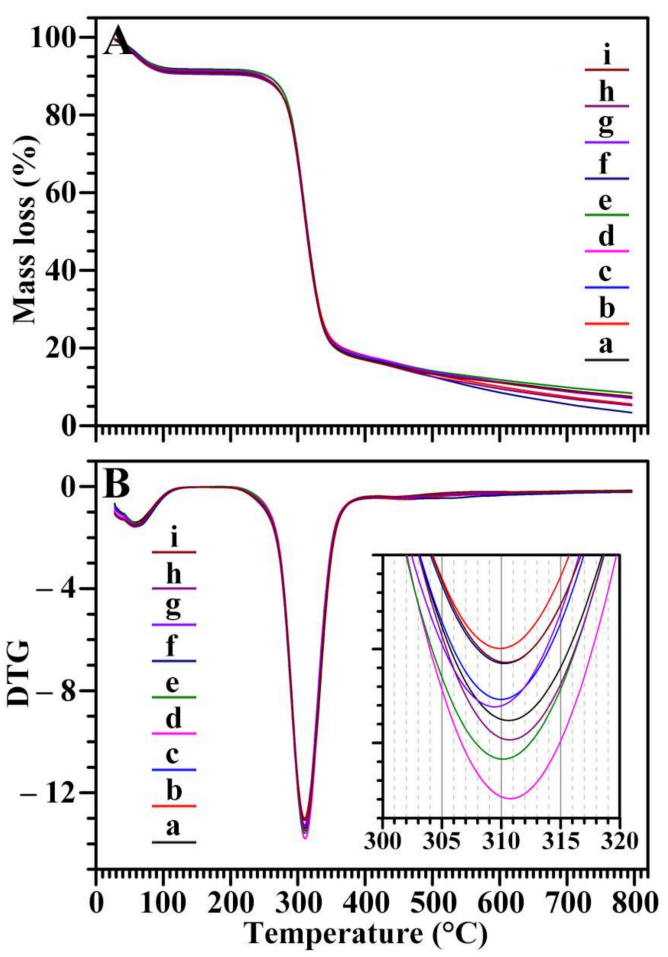

Figure 8. TGA curves (A) and DTG curves (B) of starches from variety 3113 (a), Benlizi (b), Dahongpao (c), Erqingzao (d), Heishanzhai 7 (e), Mi 5 (f), Mi 6 (g), Yangguang (h), and Yanshanhong (i). 


\subsection{Digestion Properties of Starch}

The native and gelatinized starches were in vitro digested by both porcine pancreatic amylase (PPA) and Aspergillus niger amyloglucosidase (AAG) (Table 6). Starch normally contains three starch components of rapidly digestible starch (RDS), slowly digestible starch (SDS), and resistant starch (RS) according to digestion degree for within $20 \mathrm{~min}$, between $20 \mathrm{~min}$ to $2 \mathrm{~h}$, and after $2 \mathrm{~h}$, respectively [46]. For native starch, the RDS, SDS, and RS ranged from 2.6 to $3.7 \%$, from 5.7 to $12.7 \%$, and from 84.4 to $90.7 \%$, respectively, among nine varieties. For gelatinized starch, the RDS, SDS, and RS ranged from 79.6 to $89.5 \%$, from 1.3 to $3.8 \%$, and from 7.1 to $17.4 \%$, respectively. Liu et al. [16] reported that the RDS, SDS, and RS range from 9.6 to $13.8 \%$, from 5.5 to $20.9 \%$, and from 67.5 to $84.9 \%$ among native starches from four Chinese chestnut varieties. In comparison with the results of Liu et al. [16], the chestnut starches in the present study had very low RDS and high RS. In the study of Liu et al. [16], the enzyme concentration is $30 \mathrm{U}$ PPA and 0.4 U AAG for $1 \mathrm{mg}$ starch, however, that is $0.4 \mathrm{U}$ PPA and $0.4 \mathrm{U}$ AAG for $1 \mathrm{mg}$ starch in the present study. Therefore, the low RDS and high RS in the present study was due to the low concentration of PPA and AAG in the enzyme solution. The digestion properties of native starch are affected by granule morphology and size, starch components, and crystalline structure. The gelatinization destroys the granule morphology and crystalline structure, leading to that the gelatinized starch is degraded easily, and its digestion properties are affected mainly by starch components [47-49].

Table 6. Digestion properties of starch.

\begin{tabular}{|c|c|c|c|c|c|c|}
\hline \multirow{2}{*}{ Varieties } & \multicolumn{3}{|c|}{ Native Starch } & \multicolumn{3}{|c|}{ Gelatinized Starch } \\
\hline & RDS (\%) & SDS (\%) & RS (\%) & RDS (\%) & SDS (\%) & RS (\%) \\
\hline 3113 & $2.6 \pm 0.3^{a}$ & $12.6 \pm 0.0^{c}$ & $84.8 \pm 0.3^{a}$ & $86.5 \pm 1.3^{b}$ & $3.5 \pm 0.8^{\mathrm{c}, \mathrm{d}}$ & $10.0 \pm 0.5^{b}$ \\
\hline Benlizi & $3.7 \pm 1.1^{\mathrm{a}}$ & $11.3 \pm 1.0^{\mathrm{b}, \mathrm{c}}$ & $85.0 \pm 0.1^{\mathrm{a}}$ & $84.8 \pm 0.6^{b}$ & $3.1 \pm 0.2^{b, c, d}$ & $12.1 \pm 0.8^{b, c}$ \\
\hline Dahongpao & $3.0 \pm 0.0^{\mathrm{a}}$ & $12.5 \pm 0.3^{c}$ & $84.4 \pm 0.3^{a}$ & $80.4 \pm 0.2^{\mathrm{a}}$ & $2.4 \pm 1.1^{\mathrm{a}, \mathrm{b}, \mathrm{c}, \mathrm{d}}$ & $17.3 \pm 1.3^{\mathrm{d}}$ \\
\hline Erqingzao & $3.3 \pm 1.0^{\mathrm{a}}$ & $10.0 \pm 0.2^{b}$ & $86.7 \pm 0.7^{a}$ & $80.7 \pm 1.1^{\mathrm{a}}$ & $1.9 \pm 0.6^{\mathrm{a}, \mathrm{b}, \mathrm{c}}$ & $17.4 \pm 0.9^{\mathrm{d}}$ \\
\hline $\begin{array}{c}\text { Heishanzhai } \\
7\end{array}$ & $3.5 \pm 1.3^{\mathrm{a}}$ & $5.7 \pm 0.9^{\mathrm{a}}$ & $90.7 \pm 0.4^{b}$ & $79.6 \pm 1.4^{\mathrm{a}}$ & $3.0 \pm 0.6^{\mathrm{b}, \mathrm{c}, \mathrm{d}}$ & $17.3 \pm 1.3^{\mathrm{d}}$ \\
\hline Mi 5 & $3.4 \pm 0.8^{\mathrm{a}}$ & $11.7 \pm 0.3^{b, c}$ & $84.9 \pm 0.5^{\mathrm{a}}$ & $84.8 \pm 1.3^{b}$ & $1.3 \pm 0.5^{\mathrm{a}}$ & $13.9 \pm 0.9^{c}$ \\
\hline Mi 6 & $2.9 \pm 0.1^{\mathrm{a}}$ & $11.9 \pm 0.8^{b, c}$ & $85.2 \pm 0.9^{a}$ & $86.2 \pm 1.2^{b}$ & $1.5 \pm 0.5^{\mathrm{a}, \mathrm{b}}$ & $12.3 \pm 1.6^{b, c}$ \\
\hline Yangguang & $3.0 \pm 0.0^{\mathrm{a}}$ & $10.7 \pm 0.6^{b, c}$ & $86.3 \pm 0.6^{a}$ & $84.0 \pm 1.4^{b}$ & $3.8 \pm 0.5^{\mathrm{d}}$ & $12.2 \pm 1.5^{b, c}$ \\
\hline Yanshanhong & $2.9 \pm 0.1^{\mathrm{a}}$ & $12.7 \pm 0.9^{c}$ & $84.4 \pm 1.0^{\mathrm{a}}$ & $89.5 \pm 1.3^{c}$ & $3.4 \pm 0.6^{\mathrm{c}, \mathrm{d}}$ & $7.1 \pm 0.8^{\mathrm{a}}$ \\
\hline Mean \pm SD & $3.1 \pm 0.4$ & $11.0 \pm 2.2$ & $85.8 \pm 2.0$ & $84.1 \pm 3.3$ & $2.7 \pm 0.9$ & $13.3 \pm 3.6$ \\
\hline Sig. & 0.770 & 0.006 & 0.002 & 0.562 & 0.398 & 0.292 \\
\hline
\end{tabular}

RDS: rapidly digestible starch; SDS: slowly digestible starch; RS: resistant starch. Data are means \pm standard deviations, $n=3$. Values in the same column with different superscript letters (a-d) are significantly different $(p<0.05)$. Mean \pm SD: the average value and standard deviation of nine samples. Sig.: The significance of normal distribution of nine samples by Shapiro-Wilk test.

\subsection{Principal Component Analysis}

Though many papers report the physicochemical properties of chestnut starches, the most papers report only one chestnut variety $[15,20,22,23,25-28]$, and few papers report two varieties $[19,21]$ or four varieties [16,24]. Many physicochemical properties between different papers cannot be compared due to the effects of different plant growing conditions and physicochemical measuring methods on starch properties, leading to that it is difficult in analyzing the relationships among physicochemical properties and visualizing the differences and similarities among varieties in terms of various starch properties. In the present studies, nine Chinese chestnut varieties growing under the same conditions were investigated, which make it possible to analyze the interrelationships between physicochemical properties and visualize the similarities and differences among Chinese chestnut varieties. The starch physicochemical properties with normal distribution were subjected to principal component analysis (PCA), and the results are shown in Figure 9. The first, second, and third principal components (PC1, PC2, and PC3) explained 40.2, 25.3, and $21.2 \%$, respectively, of the overall variation. The loading plot of PCA can provide the information about the interrelationships between the measured physicochemical properties of starch. The properties with curves close to each other on the plot are positively correlated while those with curves in opposite directions are significantly negatively correlated. In the present study, the loading plot of physicochemical 
properties showed that the lamellar peak intensity (PI) was negatively correlated to the absorbance ratio of $1045 / 1022 \mathrm{~cm}^{-1}$ in FTIR spectrum (IR) and the absorbance ratio of OD620 to OD550 in iodine absorbance spectrum (OD620/550). The gelatinization onset, peak, and conclusion temperatures (To, Tp, and Tc) were significantly positively correlated to the PI and negatively correlated to the IR and OD620/550. The pasting peak and breakdown viscosities (PV and BV) were negatively correlated to the gelatinization temperatures. The digestion of gelatinized starch was positively correlated to the starch iodine blue value (IBV), apparent amylose content (AAC), PV, and BV, and negatively correlated to the PI and gelatinization temperatures (Figure 9A). The score plot of PCA provides an overview of the similarities and differences between the starches of different varieties. The distance between the locations of any two starches can reflect the degree of the difference/similarity between them. The score plot showed that starches from different varieties of Chinese chestnut had some differences in their physicochemical properties (Figure 9B). For example, the Mi 6 starch was located at the far left of the score plot with a large negative score in PC1, while the Heishanzhai 7 (HSZ) starch had a large positive score, indicating that the two starches exhibited the greatest differences in their physicochemical properties, especially the properties whose curves in Figure 9A lied relatively close to the PC1 axis.
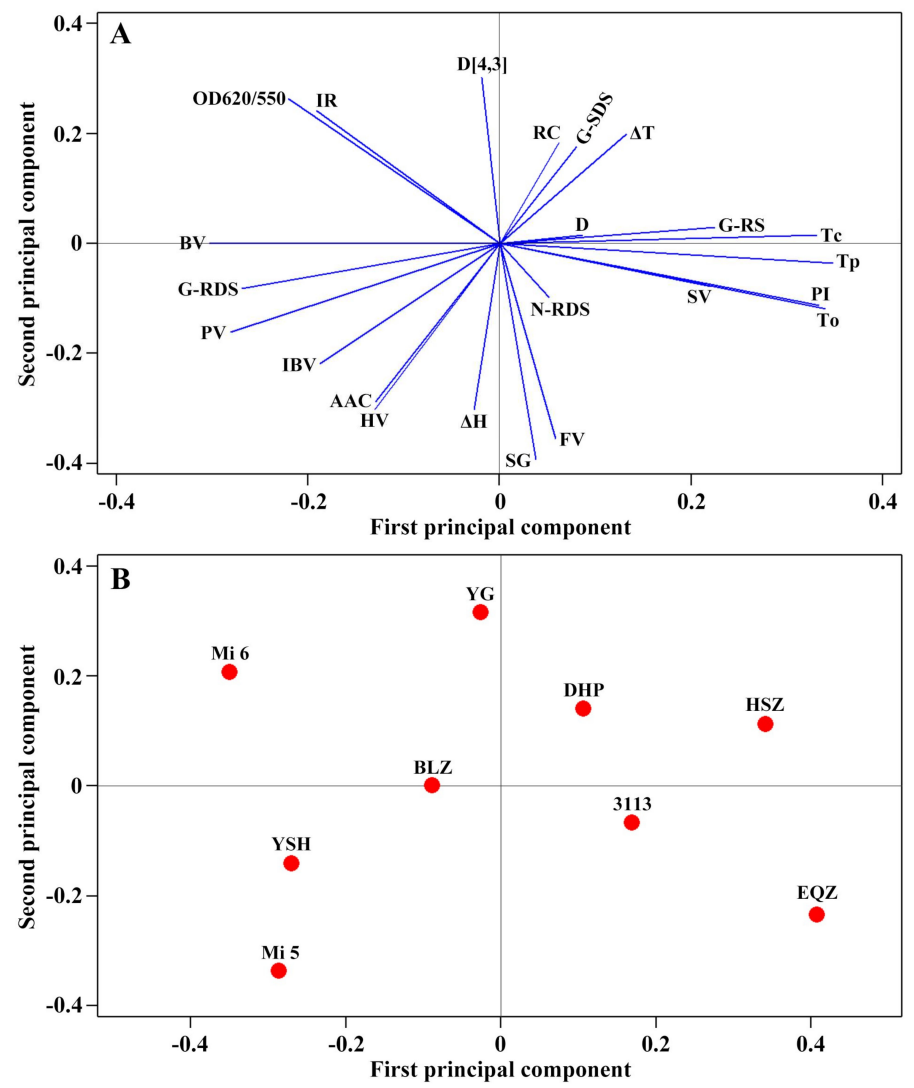

Figure 9. Loading (A) and score plots (B) of principal component analysis based on physicochemical properties of starches from nine Chinese chestnut varieties. The abbreviations in (A) are listed below: AAC, apparent amylose content; D, lamellar distance; D[4,3], volume-weighted mean diameter; IBV, iodine blue value of starch; IR, absorbance ratio of 1045/1022 $\mathrm{cm}^{-1}$ in FTIR spectrum; N-RDS, rapidly digestible starch in native starch; G-RDS, SDS, and RS, rapidly digestible starch, slowly digestible starch, and resistant starch in gelatinized starch; OD620/550, absorbance ratio of OD620 to OD550 in iodine absorbance spectrum of starch; PI, lamellar peak intensity; PV, HV, BV, FV, and SV, pasting peak, hot, breakdown, final, and setback viscosity, respectively; $\mathrm{RC}$, relative crystallinity; $\mathrm{SG}$, volume percentage of small starch granule; $\mathrm{To}, \mathrm{Tp}$, and $\mathrm{Tc}$, gelatinization onset, peak, and conclusion temperature, respectively; $\Delta \mathrm{T}$, gelatinization temperature range; $\Delta \mathrm{H}$, gelatinization enthalpy. The abbreviations of varieties in (B) are listed below: BLZ, Benlizi; DHP, Dahongpao; EQZ, Erqingzao; HSZ; Heishanzhai 7; YG, Yangguang; YSH, Yanshanhong. 


\section{Materials and Methods}

\subsection{Plant Materials}

Nine popular varieties (3113, Benlizi, Dahongpao, Erqingzao, Heishanzhai 7, Mi 5, Mi 6, Yangguang, and Yanshanhong) of Chinese chestnut (Castanea mollissima Bl.) were obtained from the Institute of Forest and Pomology, Beijing Academy of Agricultural and Forestry Sciences, China. They grew in the Shachang Village, Miyun, Beijing, China, in 2017. Their mature nuts were harvested and stored at $4{ }^{\circ} \mathrm{C}$ before use.

\subsection{Morphology, Weight, and Starch Content of Nut and Kernel}

Fresh nuts were photographed using a digital camera (IXUS 750, Canon, Tokyo, Japan). Twenty nuts were randomly chosen and weighed. Their seed coats were removed, and the obtained kernels were weighted and sliced into small pieces. The kernel pieces were dried at $110{ }^{\circ} \mathrm{C}$ for $2 \mathrm{~h}$ and $80^{\circ} \mathrm{C}$ for 2 days, and then weighted and ground extensively. The flour was passed through 100-mesh sieve, and its starch was determined using the colorimetric method of anthrone- $\mathrm{H}_{2} \mathrm{SO}_{4}$ following the method of Gao et al. [9].

\subsection{Starch Isolation}

The kernels were homogenized with $0.5 \%(w / v)$ sodium metabisulfite aqueous solution in a home blender (JYL-C93T, Joyoung, Suzhou, Jiangsu, China). The homogenate was squeezed through four layers of cheesecloth, and filtered with 100-, 200- and 300-mesh sieves. After the starch suspension was settled overnight at $4{ }^{\circ} \mathrm{C}$, the starch precipitate was dispersed in $0.2 \%(w / v) \mathrm{NaOH}$ and centrifuged (Centrifuge 5430R, Eppendorf, Hamburg, Germany) (3000× g, $5 \mathrm{~min}$ ). The starch precipitate was repeatedly treated three times using $0.2 \% \mathrm{NaOH}$, and then washed three times with distilled water and two times with anhydrous ethanol. Finally, the starch precipitate was dried at $40{ }^{\circ} \mathrm{C}$, ground into powders, and passed through a 100-mesh sieve.

\subsection{Morphology Observation and Size Distribution Analysis of Starch}

The $1 \%(w / v)$ starch suspension in 50\% (v/v) glycerol was observed and photographed using a polarized light microscope (BX 53, Olympus, Tokyo, Japan) under normal and polarized light. The dry starch powder was photographed using an environmental scanning electron microscope (ESEM XL-30, Philips, Eindhoven, Holland) following the method of Cai et al. [49]. The granule size distribution was analyzed using a laser diffraction instrument (Mastersizer 2000, Malvern, Worcestershire, UK) following the method of Cai et al. [50].

\subsection{Analysis of Iodine Absorption Spectrum and Determination of Apparent Amylose Content}

Starch was dissolved completely in urea dimethyl sulphoxide and treated with iodine solution following the method of Man et al. [51]. The iodine absorption spectrum was scanned using a spectrophotometer (Ultrospec 6300 pro, Amersham Bioscience, Cambridge, UK). The apparent amylose content was determined from absorbance at $620 \mathrm{~nm}$.

\subsection{XRD Analysis}

The starch was humidified in a moist chamber with a saturated solution of $\mathrm{NaCl}$ for 1 week. The sample was analyzed using an X-ray powder diffractometer (D8, Bruker, Karlsruhe, Germany) following the method of Cai et al. [50]. The test settings were as follows: scanning from $3^{\circ}$ to $40^{\circ} 2 \theta$, step size $0.02^{\circ}$, and X-ray beam at $200 \mathrm{~mA}$ and $40 \mathrm{kV}$. 


\subsection{ATR-FTIR Analysis}

The starch was analyzed using a FTIR spectrometer (7000, Varian, Santa Clara, CA, USA) with a DTGS detector equipped with an ATR cell following the method of Cai et al. [50]. The spectrum baseline was chosen from 1200 to $800 \mathrm{~cm}^{-1}$, and the deconvolution was carried out using a half-width of $19 \mathrm{~cm}^{-1}$ and an enhancement factor of 1.9 .

\subsection{SAXS Analysis}

The lamellar structure of starch was analyzed using a SAXS instrument (NanoStar, Bruker, Karlsruhe, Germany) equipped with Vantec 2000 detector and pin-hole collimation for point focus geometry. The test settings were described previously by Cai et al. [50].

\subsection{DSC Analysis}

Five milligrams of starch and $15 \mu \mathrm{L}$ of deionized water were mixed and sealed in an aluminum pan for $2 \mathrm{~h}$ at room temperature. The sample was scanned using a differential scanning calorimeter (200-F3, Netzsch, Selb, Germany) from 25 to $130^{\circ} \mathrm{C}$ at $10^{\circ} \mathrm{C} / \mathrm{min}$.

\subsection{RVA Analysis}

Three grams of starch was dispersed in $25 \mathrm{~mL}$ deionized water. The sample was analyzed using an RVA (3D, Newport Scientific, Warriewood, NSW, Australia). The starch-water slurry was dispersed by rotating the paddle at $960 \mathrm{rpm}$ for the first $10 \mathrm{~s}$ and then a constant speed of $160 \mathrm{rpm}$. The temperature program was set as follows: holding at $50{ }^{\circ} \mathrm{C}$ for $1 \mathrm{~min}$, heating to $95^{\circ} \mathrm{C}$ at $12{ }^{\circ} \mathrm{C} / \mathrm{min}$, maintaining at $95^{\circ} \mathrm{C}$ for $2.5 \mathrm{~min}$, cooling to $50{ }^{\circ} \mathrm{C}$ at $12{ }^{\circ} \mathrm{C} / \mathrm{min}$, and holding at $50{ }^{\circ} \mathrm{C}$ for $1.4 \mathrm{~min}$.

\subsection{TGA Analysis}

The TGA of starch was carried out using a TGA system (Pyris 1, PerkinElmer, Waltham, MA, USA) following the method of Zhang et al. [52]. The sample was heated from room temperature to $800^{\circ} \mathrm{C}$ at $10{ }^{\circ} \mathrm{C} / \mathrm{min}$. The change in sample weight against temperature was measured and analyzed.

\subsection{Determination of Digestion Properties}

The native and gelatinized starches were digested by both PPA (A3176, Sigma-Aldrich, St Louis, MO, USA) and AAG (E-AMGDF, Megazyme, Bray, Ireland) following the method of Lin et al. [53]. The gelatinized starch was prepared through heating the starch-water slurry $(10 \mathrm{mg} / \mathrm{mL})$ in a ThermoMixer $\mathrm{C}$ (Eppendorf, Hamburg, Germany) at $98{ }^{\circ} \mathrm{C}$ and $1000 \mathrm{rpm}$ for $12 \mathrm{~min}$. The native and gelatinized starches were incubated in enzyme solution $(20 \mathrm{mM}$ sodium phosphate buffer, $\mathrm{pH}$ 6.0, $6.7 \mathrm{mM} \mathrm{NaCl}, 0.01 \% \mathrm{NaN}_{3}, 2.5 \mathrm{mM} \mathrm{CaCl} 2$, PPA $(4 \mathrm{U} / 10 \mathrm{mg})$, and AAG $(4 \mathrm{U} / 10 \mathrm{mg})$ ) at $37^{\circ} \mathrm{C}$ using a ThermoMixer C (Eppendorf, Hamburg, Germany) with shaking at $1000 \mathrm{rpm}$. The released glucose was determined using a glucose assay kit (K-GLUC, Megazyme, Bray, Ireland).

\subsection{Statistical Analysis}

The one-way analysis of variance with post hoc contrasts by Tukey's test and the normal distribution of all measuring data by Shapiro-Wild test were carried out using the SPSS 19.0 Statistical Software Program (IBM Company, Chicago, IL, USA). The physicochemical properties with the significance of normal distribution over 0.05 were used for principle component analysis using Minitab V. 16.0 software (IBM Company, Chicago, IL, USA).

\section{Conclusions}

Chinese chestnut kernels have high starch content and are an important starch source. Starches from different varieties growing under the same conditions showed some differences in their physicochemical properties. The lamellar peak intensity was negatively correlated to the 
ordered structure. The gelatinization temperatures were significantly positively correlated to the lamellar peak intensity and negatively correlated to the ordered structure. The pasting peak and breakdown viscosities were negatively correlated to the gelatinization temperatures. The digestion of gelatinized starch was positively correlated to the apparent amylose content and the pasting peak and breakdown viscosity, and negatively correlated to the lamellar peak intensity and the gelatinization temperatures. This study could provide some information for the quality breeding of Chinese chestnut varieties and their applications.

Author Contributions: C.W. conceived the study and designed the experiments; L.Z., T.L., G.H., and K.G. performed the experiments; and C.W. and L.Z. wrote the manuscript. All authors discussed the contents of the manuscript and approved the submission.

Funding: This study was financially supported by grants from the National Natural Science Foundation of China (31570324), the Qing Lan Project of Jiangsu Province, the Talent Project of Yangzhou University, and the Priority Academic Program Development of Jiangsu Higher Education Institutions.

Conflicts of Interest: The authors declare no conflict of interest. The founding sponsors had no role in the design of the study; in the collection, analyses, or interpretation of data; in the writing of the manuscript; or in the decision to publish the results.

\section{References}

1. Emmambux, M.N.; Taylor, J.R.N. Morphology, physical, chemical, and functional properties of starches from cereals, legumes, and tubers cultivated in Afria: A review. Starch 2013, 65, 715-729. [CrossRef]

2. García, N.L.; Famá, L.; Dufresne, A.; Aranguren, M.; Goyanes, S. A comparison between the physic-chemical properties of tuber and cereal starches. Food Res. Int. 2009, 42, 976-982. [CrossRef]

3. Liu, Q.; Donner, E.; Yin, Y.; Huang, R.L.; Fan, M.Z. The physicochemical properties and in vitro digestibility of selected cereals, tubers and legumes grown in China. Food Chem. 2006, 99, 470-477. [CrossRef]

4. Hoover, R. Composition, molecular structure, and physicochemical properties of tuber and root starches: A review. Carbohydr. Polym. 2001, 45, 253-267. [CrossRef]

5. Wani, I.A.; Sogi, D.S.; Hamdani, A.M.; Gani, A.; Bhat, N.A.; Shah, A. Isolation, composition, and physicochemical properties of starch from legumes: A review. Starch 2016, 68, 1-12. [CrossRef]

6. Guo, K.; Lin, L.; Fan, X.; Zhang, L.; Wei, C. Comparison of structural and functional properties of starches from five fruit kernels. Food Chem. 2018, 257, 75-82. [CrossRef]

7. Fan, X.; Zhang, S.; Lin, L.; Zhao, L.; Liu, A.; Wei, C. Properties of new starches from tubers of Arisaema elephas, yunnanense and erubescens. Food Hydrocolloid. 2016, 61, 183-190. [CrossRef]

8. Huang, J.; Zhao, L.; Man, J.; Wang, J.; Zhou, W.; Huai, H.; Wei, C. Comparison of physicochemical properties of B-type nontraditional starches from different sources. Int. J. Biol. Macromol. 2015, 78, 165-172. [CrossRef]

9. Gao, H.; Cai, J.; Han, W.; Huai, H.; Chen, Y.; Wei, C. Comparison of starches isolated from three different Trapa species. Food Hydrocolloid. 2014, 37, 174-181. [CrossRef]

10. Huang, J.; Zhao, L.; Huai, H.; Li, E.; Zhang, F.; Wei, C. Structural and functional properties of starches from wild Trapa quadrispinosa, japonica, mammillifera and incise. Food Hydrocolloid. 2015, 48, 117-126. [CrossRef]

11. Zhu, F. Properties and food uses of chestnut flour and starch. Food Bioprocess. Technol. 2017, 10, $1173-1191$. [CrossRef]

12. FAOSTAT. Available online: http://www.fao.org/faostat/en/\#data/QC/visualize (accessed on 12 October 2018).

13. De Vasconcelos, M.C.B.M.; Bennett, R.N.; Rosa, E.A.S.; Ferreira-Cardoso, J.V. Composition of European chestnut (Castanea sativa Mill.) and association with health effects: Fresh and processed products. J. Sci. Food Agric. 2010, 90, 1578-1589. [CrossRef] [PubMed]

14. Frati, A.; Landi, D.; Marinelli, C.; Gianni, G.; Fontana, L.; Migliorini, M.; Pierucci, F.; Garcia-Gil, M.; Meacci, E. Nutraceutical properties of chestnut flours: Beneficial effects on skeletal muscle atrophy. Food Funct. 2014, 5, 2870-2882. [CrossRef] [PubMed]

15. Demiate, I.M.; Oetterer, M.; Wosiacki, G. Characterization of chestnut (Castanea sativa, Mill) starch for industrial utilization. Braz. Arch. Biol. Techn. 2001, 44, 69-78. [CrossRef]

16. Liu, C.; Wang, S.; Chang, X.; Wang, S. Structural and functional properties of starches from Chinese chestnuts. Food Hydrocolloid. 2015, 43, 568-576. [CrossRef] 
17. Silva, A.P.; Oliveira, I.; Silva, M.E.; Guedes, C.M.; Borges, O.; Magalhães, B. Starch characterization in seven raw, boiled and roasted chestnuts (Castanea sativa Mill.) cultivars from Portugal. J. Food Sci. Technol. 2016, 53, 348-358. [CrossRef] [PubMed]

18. Hao, H.; Li, Q.; Bao, W.; Wu, Y.; Ouyang, J. Relationship between physicochemical characteristics and in vitro digestibility of chestnut (Castanea mollissima) starch. Food Hydrocolloid. 2018, 84, 193-194. [CrossRef]

19. Correia, P.R.; Nunes, M.C.; Beirão-da-Costa, M.L. The effect of starch isolation method on physical and functional properties of Portuguese nuts starches. I. Chestnuts (Castanea sativa Mill. var. Martainha and Longal) fruits. Food Hydrocolloid. 2012, 27, 256-263. [CrossRef]

20. Cruz, B.R.; Abraão, A.S.; Lemos, A.M.; Nunes, F.M. Chemical composition and functional properties of native chestnut starch (Castanea sativa Mill). Carbohyd. Polym. 2013, 94, 594-602. [CrossRef]

21. Lemos, A.M.; Abraão, A.S.; Cruz, B.R.; Morgado, M.L.; Rebelo, M.; Nunes, F.M. Effect of granular characteristics on the viscoelastic and mechanical properties of native chestnut starch (Castanea sativa Mill). Food Hydrocolloid. 2015, 51, 305-317. [CrossRef]

22. Zhang, M.; Chen, H.; Zhang, Y. Physicochemical, thermal, and pasting properties of Chinese chestnut (Castanea mollissima Bl.) starches as affected by different drying methods. Starch 2011, 63, 260-267. [CrossRef]

23. Yang, B.; Jiang, G.; Prasad, K.N.; Gu, C.; Jiang, Y. Crystalline, thermal and textural characteristics of starches isolated from chestnut (Castanea mollissima Bl.) seeds at different degrees of hardness. Food Chem. 2010, 119, 995-999. [CrossRef]

24. Wang, S.; Liu, C.; Wang, S. Drying methods used in starch isolation change properties of C-type chestnut (Castanea mollissima) starches. LWT-Food Sci. Technol. 2016, 73, 663-669. [CrossRef]

25. Kan, L.; Li, Q.; Xie, S.; Hu, J.; Wu, Y.; Ouyang, J. Effect of thermal processing on the physicochemical properties of chestnut starch and textural profile of chestnut kernel. Carbohyd. Polym. 2016, 151, 614-623. [CrossRef]

26. Chen, L.; Lu, D.; Wang, T.; Li, Z.; Zhao, Y.; Jiang, Y.; Zhang, Q.; Cao, Q.; Fang, K.; Xing, Y.; et al. Identification and expression analysis of starch branching enzymes involved in starch synthesis during the development of chestnut (Castanea mollissima Blume) cotyledons. PLoS ONE 2017, 12, e0177792. [CrossRef] [PubMed]

27. Zhao, J.; Zhang, Y.; Wu, Y.; Liu, L.; Ouyang, J. Physicochemical properties and in vitro digestibility of starch from naturally air-dried chestnut. Int. J. Biol. Macromol. 2018, 117, 1074-1080. [CrossRef] [PubMed]

28. Zhang, L.; Lin, Q.; Feng, Y.; Fan, X.; Zou, F.; Yuan, D.Y.; Zeng, X.; Cao, H. Transcriptomic identification and expression of starch and sucrose metabolism genes in the seeds of Chinese chestnut (Castanea mollissima). J. Agric. Food Chem. 2015, 63, 929-942. [CrossRef] [PubMed]

29. Yoo, S.H.; Lee, C.S.; Kim, B.S.; Shin, M. The properties and molecular structures of gusiljatbam starch compared to those of acorn and chestnut starches. Starch 2012, 64, 339-347. [CrossRef]

30. Torres, M.D.; Moreira, R.; Chenlo, F.; Morel, M.H.; Barron, C. Physicochemical and structural properties of starch isolated from fresh and dried chestnuts and chestnut flour. Food Technol. Biotechnol. 2014, 52, 135-139.

31. Lindeboom, N.; Chang, P.R.; Tyler, R.T. Analytical, biochemical and physicochemical aspects of starch granule size, with emphasis on small granule starches: A review. Starch 2004, 56, 89-99. [CrossRef]

32. Wei, C.; Zhang, J.; Chen, Y.; Zhou, W.; Xu, B.; Wang, Y.; Chen, J. Physicochemical properties and development of wheat large and small starch granules during endosperm development. Acta Physiol. Plant. 2010, 32, 905-916. [CrossRef]

33. Naguleswaran, S.; Li, J.; Vasanthan, T.; Bressler, D.; Hoover, R. Amylolysis of large and small granules of native triticale, wheat and corn starches using a mixture of $\alpha$-amylase and glucoamylase. Carbohydr. Polym. 2012, 88, 864-874. [CrossRef]

34. He, W.; Wei, C. Progress in C-type starches from different plant sources. Food Hydrocolloid. 2017, 73, $162-175$. [CrossRef]

35. Atichokudomchai, N.; Varavinit, S.; Chinachoti, P. A study of ordered structure in acid-modified tapioca starch by ${ }^{13} \mathrm{C}$ CP/MAS solid-state NMR. Carbohydr. Polym. 2004, 58, 383-389. [CrossRef]

36. Sevenou, O.; Hill, S.E.; Farhat, I.A.; Mitchell, J.R. Organisation of the external region of the starch granule as determined by infrared spectroscopy. Int. J. Biol. Macromol. 2002, 31, 79-85. [CrossRef]

37. Blazek, J.; Gilbert, E.P. Application of small-angle X-ray and neutron scattering techniques to the characterisation of starch structure: A review. Carbohydr. Polym. 2011, 85, 281-293. [CrossRef] 
38. Yuryev, V.P.; Krivandin, A.V.; Kiseleva, V.I.; Wasserman, L.A.; Genkina, N.K.; Fornal, J.; Blaszczak, W.; Schiraldi, A. Structural parameters of amylopectin clusters and semi-crystalline growth rings in wheat starches with different amylose content. Carbohydr. Res. 2004, 339, 2683-2691. [CrossRef]

39. Lee, J.W.; Choi, H.W.; Seo, D.H.; Park, J.D.; Kum, J.S.; Kim, B.Y.; Baik, M.Y. Isolation and characterization of starches from chestnuts cultivated in three regions in Korea. Starch 2015, 67, 585-594. [CrossRef]

40. Wang, S.; Copeland, L. Phase transitions of pea starch over a wide range of water content. J. Agric. Food Chem. 2012, 60, 6439-6446. [CrossRef] [PubMed]

41. Rincón-Londoño, N.; Vega-Rojas, L.J.; Contreras-Padilla, M.; Acosta-Osorio, A.A.; Rodríguez-García, M.E. Analysis of the pasting profile in corn starch: Structural, morphological, and thermal transformations, Part I. Int. J. Biol. Macromol. 2016, 91, 106-114. [CrossRef] [PubMed]

42. Rincón-Londoño, N.; Millan-Malo, B.; Rodríguez-García, M.E. Analysis of thermal pasting profile in corn starch rich in amylose and amylopectin: Physicochemical transformations, Part II. Int. J. Biol. Macromol. 2016, 89, 43-53. [CrossRef] [PubMed]

43. Abegunde, O.K.; Mu, T.H.; Chen, J.W.; Deng, F.M. Physicochemical characterization of sweet potato starches popularly used in Chinese starch industry. Food Hydrocolloid. 2013, 33, 169-177. [CrossRef]

44. Singh, N.; Kaur, L.; Ezekiel, R.; Guraya, H.S. Microstructural, cooking and textural characteristics of potato (Solanum tuberosum L.) tubers in relation to physicochemical and functional properties of their flours. J. Sci. Food Agric. 2005, 85, 1275-1284. [CrossRef]

45. Wang, L.; Xie, B.; Xiong, G.; Du, X.; Qiao, Y.; Liao, L. Study on the granular characteristics of starches separated from Chinese rice cultivars. Carbohydr. Polym. 2012, 87, 1038-1044. [CrossRef]

46. Englyst, H.N.; Kingman, S.M.; Cummings, J.H. Classification and measurement of nutritionally important starch fractions. Eur. J. Clin. Nutr. 1992, 45, S33-S50.

47. Lin, L.; Cai, C.; Gilbert, R.G.; Li, E.; Wang, J.; Wei, C. Relationships between amylopectin molecular structures and functional properties of different-sized fractions of normal and high-amylose maize starches. Food Hydrocolloid. 2016, 52, 359-368. [CrossRef]

48. Lin, L.; Guo, D.; Huang, J.; Zhang, X.; Zhang, L.; Wei, C. Molecular structure and enzymatic hydrolysis properties of starches from high-amylose maize inbred lines and their hybrids. Food Hydrocolloid. 2016, 58, 246-254. [CrossRef]

49. Wang, S.; Copeland, L. Molecular disassembly of starch granules during gelatinization and its effect on starch digestibility: A review. Food Funct. 2013, 4, 1564-1580. [CrossRef]

50. Cai, C.; Lin, L.; Man, J.; Zhao, L.; Wang, Z.; Wei, C. Different structural properties of high-amylose maize starch fractions varying in granule size. J. Agric. Food Chem. 2014, 62, 11711-11721. [CrossRef]

51. Man, J.; Lin, L.; Wang, Z.; Wang, Y.; Liu, Q.; Wei, C. Different structure of heterogeneous starch granules from high-amylose rice. J. Agric. Food Chem. 2014, 62, 11254-11263. [CrossRef]

52. Zhang, B.; Guo, K.; Lin, L.; Wei, C. Comparison of structural and functional properties of starches from the rhizome and bulbil of Chinese yam (Dioscorea opposite Thunb.). Molecules 2018, 23, 427. [CrossRef] [PubMed]

53. Lin, L.; Zhang, Q.; Zhang, L.; Wei, C. Evaluation of the molecular structural parameters of normal rice starch and their relationships with its thermal and digestion properties. Molecules 2017, 22, 1526. [CrossRef] [PubMed]

Sample Availability: Samples of the starches are available from the authors.

(C) 2018 by the authors. Licensee MDPI, Basel, Switzerland. This article is an open access article distributed under the terms and conditions of the Creative Commons Attribution (CC BY) license (http:/ / creativecommons.org/licenses/by/4.0/). 